\title{
Correspondence
}

Epidemiol. Infect. (2013).

doi: $10.1017 /$ S0950268812000775

First published online 7 June 2012

\section{Spatial incidence of dengue infections in Queensland, Australia}

To the Editor:

The paper by $\mathrm{Hu}$ et al. on the spatial incidence of dengue infections in Queensland, Australia [1], has a serious, indeed fatal, flaw. There has not been any recognized locally acquired dengue in Queensland south of the city of Townsville (in the north of the state) since the mid-1950s when dengue transmission occurred in Rockhampton [2, 3]. Therefore, the maps (Figures 3-5) in the paper that indicate dengue incidence, inferring local transmission of dengue south of Townsville, are not only quite incorrect but also misleading. Unfortunately this misleading inference has already been cited in an Australian Government report on the likely impact of climate change in Australia [4], and consequently that report should be revised.

The error has occurred because $\mathrm{Hu}$ et al. have not carefully checked the data supplied to them by Queensland Health. A travel history is obtained for each notification of dengue in Queensland so that a determination on the place of acquisition can be made. The dataset supplied by Queensland Health contained numbers of dengue cases 'acquired locally and overseas' [1]. However, $\mathrm{Hu}$ et al. ignored this information and failed to either separate locally acquired cases from imported cases or to determine where the locally acquired cases were actually acquired, and included all cases to estimate local incidences based on residential postcodes. This failing has led to the quite erroneous conclusion that "dengue transmission had already begun to extend southeasternwards in Queensland between 1993 and 2004' [1]; it hadn't, and indeed still has not.

\section{Declaration of Interest}

None.

\section{References}

1. Hu W, et al. Spatial analysis of notified dengue fever infections. Epidemiology and Infection 2011; 139: 391-399.

2. Kay BH, et al. Dengue fever: reappearance in northern Queensland after 26 years. Medical Journal of Australia 1984; 140: 264-268.

3. Hanna JN, Ritchie SA. Outbreaks of dengue in north Queensland, 1990-2008. Communicable Diseases Intelligence 2009; 33: 32-33. [An updated version of the Table is available upon request.]

4. Hughes L. McMichael T (Climate Commission). The critical decade: climate change and health. Commonwealth of Australia (Department of Climate Change and Energy Efficiency), 2011, pp. 19-21 (http://climate commission.gov.au/wp-content/uploads/111129_FINALFOR-WEB.pdf). Accessed 30 January 2012.

SCOTTA. RITCHIE ${ }^{1}$, PhD, FACTM, JEFFREY N. HANNA ${ }^{2}$, MPH, FAFPHM, FACTM, CHRISTINE E. SELVEY ${ }^{3}$, MBBS, MSc, RICHARD C. RUSSELL ${ }^{4}$, PhD, FACTM

${ }^{1}$ Professor, School of Public Health, Tropical Medicine and Rehabilitation Sciences, James Cook University, Cairns

${ }^{2}$ Associate Professor, School of Public Health, Tropical Medicine and Rehabilitation Sciences, James Cook

University, Cairns.

${ }^{3}$ Senior Director, Communicable Diseases Branch, Queensland Health, Brisbane

${ }^{4}$ Professor of Medical Entomology, Sydney Medical School, University of Sydney Director, Department of Medical Entomology, CIDM and SEIB, Westmead Hospital, Sydney

Author for correspondence:

Professor J. N. Hanna School of Public Health, Tropical

Medicine and Rehabilitation Sciences, James Cook

University, Cairns.

(Email: jeffrey.hanna@jcu.edu.au) 